\title{
0 Rio do IV Centenário aos 450 anos: novas funções da cidade e o passado como obstáculo
}

\author{
Mario Brum \\ Rafael Soares Gonçalves*
}

\begin{abstract}
Resumo
As datas comemorativas dos 400 e 450 anos da cidade apresentam semelhanças: mudanças nas funções da cidade, novos projetos para a cidade, expansão baseada na superação da geografia e um diálogo complexo com o seu passado. O presente artigo dará uma ênfase especial aos projetos de habitação popular desses períodos, sobretudo em relação às favelas. Mesmo sem estarem diretamente relacionadas com as comemorações, as intervenções nas favelas, ontem e hoje, geram sempre acirrados debates e revelam modelos urbanos, que dialogam pouco com o que o Rio tem de mais interessante: a diversidade das suas formas de ocupação urbana. Pretende-se comparar o modelo de cidade dos 400 anos e o que se desenha atualmente, sublinhando as diferenças e convergências desses dois períodos.
\end{abstract}

Palavras-chave: Rio de Janeiro; comemorações dos 400 e 450 anos; favelas; política habitacional.

\begin{abstract}
The Commemorative dates of 400 and 450 years of the city present similarities: changes in the functions of the city, new projects for the city, expansion based on overcoming geography and a complex dialogue with the past of the city. This article will give a special emphasis to the popular housing projects of these periods, especially in relation to the favelas. Even without being directly related to the celebrations, interventions in the favelas, yesterday and today, generate discussion and reveal urban models that not dialogue with the most interesting aspects of Rio de Janeiro: the diversity of her urban occupation. The aim is to compare the model of the city of 400 years and which draws today underlining the differences and similarities of these two periods.
\end{abstract}

Keywords: Rio de Janeiro; the commemoratives of 400 and 450 years; favelas; housing politics.

\footnotetext{
* Mario Brum: Doutor em História (UFF), pós-doutor em Planejamento Urbano (UFRJ) e pós-doutorando FEBF-UERJ/CAPES. mariobrum@yahoo. com.br

Rafael Soares Gonçalves: Advogado, doutor em História (Univ. de Paris VII), pós-doutor em Antropologia (EHESS), professor adjunto do Departamento de Serviço Social da PUC-Rio.rafaelsgoncalves@yahoo.com.br
} 


\section{Introdução}

"O Rio cresce. Túneis, viadutos, avenidas, novas pistas rasgam caminhos para a cidade que se expande, se moderniza e ganha outra dimensão. (...) E o Rio está em obras. Ele se apronta para um importante acontecimento em sua história...”

O trecho acima que poderia ser a cobertura atual sobre a preparação da cidade para os Grandes Eventos é, na verdade, a introdução do 'Caderno da Cidade' do Jornal do Brasil de 07 de dezembro de 1962. O ‘importante acontecimento’ era o IV Centenário da cidade, que mais do que mera celebração de uma trajetória pretérita da cidade, tratava-se de projetar uma imagem otimista para o futuro. A mesma reportagem do Jornal do Brasil, aliás, com forte entusiasmo dos feitos do governador Lacerda, sublinhava a nova vocação da cidade:

O estado da Guanabara, a cidade do Rio de Janeiro, ou, simplesmente, o Rio, a cidade-Estado, está mudando de roupagem. Em poucos anos está se tornando uma cidade moderna, realmente habitável. E, em 1965, exatamente quatrocentos anos depois de sua fundação, concluídas as principais obras, o Rio voltará a ser a cidade maravilhosa.

A nova cidade-estado da Guanabara buscava reafirmar o seu título de 'Cidade Maravilhosa', mesmo não sendo mais a capital do país. Tratava-se, assim, de reforçar tanto o potencial econômico da cidade quanto o seu papel de vitrine do Brasil, celebrando o orgulho da 'Belacap', a bela capital, em oposição à inaugurada dois anos antes: Brasília, a 'Novacap’. Intentava-se projetar um Rio para o futuro, resolvendo, não sem conflitos e questionamentos, velhas questões que a cidade precisava superar para que pudesse exercer novas funções e mantivesse papel de destaque no cenário nacional.

Problemas como os tratados pelo jornalista David Nasser, em tom irônico, num editorial da revista $O$ Cruzeiro quando da mudança da capital:

\footnotetext{
Ganhamos a liberdade de ser município sem os ônus de Capital da República. Somos ao mesmo tempo cidade, município e capital de município. Um pedacinho de terra, feliz, do Joá a Santa Cruz. Ficamos com o nosso Corpo de Bombeiros valente e mal pago, com a nossa policiazinha mambembe viajando de bonde, com a nossa falta de água, com a nossa falta de telefones, com as nossas enchentes. Mas os nossos problemas são, de agora em diante, inteiramente nossos. Não precisamos transferi-los ao Arquiprefeito, que era, nesta cidade, o Presidente da República. (Nasser, 1960)
}

Assim, no começo da década de 1960, a cidade passaria uma vez mais por um conjunto de reformas que atendiam interesses econômicos em moldar a cidade para as funções desejadas, tentando ampliar sua mobilidade e ordenar o espaço urbano, num esforço conjugado com as autoridades no poder que intentavam dar uma nova face ao Rio, não mais à capital da República.

Processo similar ao que o Rio de Janeiro vive agora: além de sediar megaeventos, a cidade se tornou destacado polo de atração de investimentos nacionais e internacionais, ${ }^{1}$ rompendo a sensação de 'crise' que viveu intensamente nas décadas de 1980 a $2000{ }^{2}$ Em um curto espaço de tempo, o Rio de Janeiro foi e será sede de quase todos os grandes eventos internacionais. Tais eventos têm permitido a mobilização de vultosos recursos para a construção de estádios e de infraestrutura necessária, sobretudo no campo da mobilidade.

1 Segundo dados da FIRJAN (Federação das Indústrias do Estado do Rio de Janeiro), o Estado do Rio tem maior concentração de investimentos do mundo. Ver em: http://www.firjan.org.br/data/pages/2C908CEC32686D3D013281E03F48787B.htm. Consultado em 22/05/2014.

20 termo 'Década de Ouro' foi largamente utilizado pela Prefeitura do Rio de Janeiro no Réveillon de 2011. Ver: "Réveillon 2011 vai inaugurar 'Década de Ouro' no Rio", em http://www.rio.rj.gov.br/web/riotur/exibeconteudo?id=1127037. Consultado em 11/06/2014. 
Duas direções de ocupação urbana se consolidam atualmente: de um lado, a expansão da cidade para o Oeste, sobretudo em direção ao bairro da Barra da Tijuca e arredores. O antigo autódromo de Jacarepaguá e o bairro de Deodoro, por exemplo, receberão grande parte dos equipamentos esportivos para os Jogos Olímpicos. Tanto a expansão do metrô quanto o surgimento de um novo modal de transporte, o BRT (sigla de Bus Rapid Transit), consolidam a ocupação da Zona Oeste e asseguram forte centralidade ao bairro da Barra da Tijuca. De outro lado, há um esforço de retorno ao centro histórico, que se manifesta, sobretudo, no faraônico projeto de urbanização da área portuária - o Projeto Porto Maravilha.

No período que antecede a comemoração dos 400 anos da cidade (em 1965), o governo Lacerda intentava alterar profundamente a dinâmica urbana da cidade através da reordenação de zonas urbanas, em que as áreas centrais iriam adquirir funções residenciais, comerciais e administrativas enquanto as zonas periféricas seriam industriais (mas também dotadas de moradias para baixa renda que trabalharia na indústria). A expansão urbana se daria nas direções norte e oeste, mas também no melhor aproveitamento das áreas já existentes, em que a ação do Estado iria 'corrigir' distorções do crescimento anterior, tendo as favelas das áreas centrais, notadamente as da Zona Sul, como alvo privilegiado desse ajuste (Brum, 2012). Guiando a expansão e garantindo um bom funcionamento da cidade para as próximas décadas, haveria um precursor plano diretor, o Plano Doxiadis. Por fim, integrando as diversas zonas da cidade, um sistema racional de novas vias expressas e a consolidação de um modal de transporte (o ônibus) ampliariam a mobilidade urbana.

No ciclo atual, porém, diante de tantos eventos de forte impacto internacional, a comemoração dos 450 anos da cidade, em 2015, ficou um pouco esquecida. Se as menções aos 400 anos do Rio de Janeiro já eram comuns quase uma década antes da data, ${ }^{3}$ as dos 450 anos só começaram a ganhar mais consistência a partir de 2014, após o lançamento da marca oficial das comemorações.

Nas duas datas vemos em curso processos muito similares: mudanças nas funções da cidade, projeção de um futuro que se quer alcançar, expansão baseada na superação da geografia e um diálogo complexo com o seu passado. Daremos ênfase especial aos projetos de habitação popular desses períodos, sobretudo em relação às favelas. Mesmo sem estarem diretamente relacionadas com as comemorações, as intervenções nas favelas, ontem e hoje, geram sempre acirrados debates e revelam modelos urbanos, que dialogam pouco com o que o Rio tem de mais interessante: a diversidade das suas formas de ocupação urbana. A diversidade é, como lembram Vogel e Mello (1985:71), uma dimensão sem a qual o lugar não pode ser imaginado. Trata-se, assim, de um elemento estrutural das relações socioespaciais cariocas.

O presente artigo pretende analisar os modelos de cidade que emergem, com suas projeções e representações, desses dois momentos históricos distintos, os 400 anos (cuja comemoração ficou mais conhecida pelo epíteto de "IV Centenário”) e os 450 anos da cidade. Em primeiro lugar, analisaremos o contexto político do recém-criado Estado da Guanabara, dando ênfase no projeto de cidade que se desenhava e que foi consolidado pelo plano urbanístico elaborado pelo escritório do arquiteto grego Doxiadis. Em um segundo modelo,

3 Podemos citar, por exemplo, a criação, sob o governo de Negrão de Lima no governo do Distrito Federal, da comissão preparatória das comemorações do IV Centenário pelo Decreto $n^{0} 13.467$ de $1^{0}$ de março de 1957 (Guimarães, 1965). Podemos citar, ainda, 0 artigo $1^{0}$ dos Estatutos da Cruzada São Sebastião, de 1955, que afirmava que a sua finalidade era dar solução humana e cristã ao problema das favelas do Rio de Janeiro, afirmando no seu parágrafo único que a Cruzada terá em vista, de modo especial, o IV Centenário da Cidade do Rio de Janeiro (20 de janeiro de 1967), como "data ideal para a completa urbanização das favelas da cidade" (Arquivo Nacional, fundo Paulo A. Ribeiro, caixa 13). 
pretende-se comparar o modelo de cidade dos 400 anos e o que se desenha atualmente, sublinhando as diferenças e convergências desses dois períodos.

\section{Carlos Lacerda: a Guanabara como vitrine do Brasil}

O status a ser adquirido pelo Rio com a transferência da capital, que se tornou realidade com a inauguração de Brasília em 21 de abril de 1960, vinha sendo objeto de debates desde a década de 1940, considerando que o projeto da construção de uma capital no Planalto Central datava do século XIX (Tamanini, 2003) e já constava, inclusive, na Constituição de 1891. ${ }^{4}$ A partir de 1958, quando se inicia a construção da nova capital, o debate sobre os possíveis destinos da futura ex-capital se acirrou, estando entre a sua absorção pelo Estado do Rio de Janeiro ou a transformação como ente autônomo dentro da Federação na condição de Estado da Guanabara. A polêmica adentrou o ano de 1960 e, em 12 de abril, a dias da inauguração da nova capital, a Lei 3752/60 finalmente definia qual seria a situação jurídica do Rio de Janeiro, criando o Estado da Guanabara.

O novo estado foi governado interinamente por Sette Câmara (nomeado por Juscelino Kubistchek) até 5 de dezembro daquele ano, quando tomaria posse seu primeiro governador. As eleições, em outubro de 1960, marcariam a primeira vez em que os cariocas escolheriam diretamente quem iria administrar a cidade.

Deste modo, o debate se pautou principalmente sobre qual seria o futuro do Rio. Se a manutenção da proeminência simbólica e econômica da cidade no cenário nacional era um anseio comum provavelmente a todos os cariocas, para Carlos Lacerda, o projeto ia ao encontro de suas aspirações políticas de concorrer à sucessão presidencial em 1965, pela União Democrática Nacional (UDN), partido de oposição desde a queda do Estado Novo, em 1945.

Vencendo o segundo colocado, Sergio Magalhães, do PTB (Partido Trabalhista Brasileiro), por uma diferença apertada de votos, pouco mais de $2 \%$, Lacerda soube explorar habilmente o novo status do Rio de Janeiro como estado autônomo, pautando sua campanha em questões locais e atribuindo aos adversários uma excessiva preocupação com questões mais gerais e 'externas' à cidade, ao invés de apontarem soluções para os temas do cotidiano da população, como, por exemplo, o crônico problema do abastecimento d'água. ${ }^{5}$ Também a polarizada conjuntura política lhe serviu para reafirmar uma identidade 'localista' em oposição aos adversários, em que manteria a autonomia da Guanabara em relação ao governo federal. O editorial do Jornal do Brasil sobre a posse de Lacerda destaca essa característica do novo governador: "A presença do sr. Lacerda no palácio que tem o nome do Estado é uma garantia que a antiga Capital do Brasil vai afirmar sua vocação autonomista de maneira a não deixar dúvidas" (Jornal do Brasil, 06/12/1960 p. 2).

O político de artigos e discursos inflamados, cuja carreira foi construída com base no mais ferrenho oposicionismo, teria de se mostrar agora um bom administrador para se fortalecer como candidato à Presidência. Mantendo a cidade-estado, e particularmente sua

40 seu artigo $3^{\circ}$ anunciava que ficaria pertencendo à União, no planalto central da República, uma zona de 14.400 quilômetros quadrados, que seria oportunamente demarcada para nela estabelecer a futura Capital Federal. Efetuada a mudança da Capital, 0 atual Distrito Federal passaria a constituir um Estado.

5 Além de inúmeras obras viárias e de infraestrutura de serviços urbanos, Lacerda colocou as bases da divisão administrativa moderna da cidade com a criação das primeiras Regiões Administrativas. 
administração em evidência, Lacerda se capitalizava politicamente, afinal, ainda que o Rio não fosse mais a capital da República, mantinha a sua importância no país. Segundo Lacerda:

\footnotetext{
o estado da Guanabara é dos mais responsáveis, e, sem dúvida, o mais preparado para influir na condução geral do país. Pela composição de seu povo, soma de todos os povos do Brasil; pela sua vocação atlântica que lhe dá um sentido universal da política, que lhe aguça a sensibilidade sem lhe particularizar paixões provincianas; pelas suas tradições de antiga capital, ainda não substituída pela aglomeração de prédios na qual, contrafeitos, acampam os três poderes da República; pela novidade impetuosa de sua ascensão à categoria de estado federado, a unidade que nos incumbe governar estará em condições de cumprir os seus deveres para com a generosa pátria comum que nos abriga. (Jornal do Brasil, 06/12/1960 p. 4)
}

Desse modo, a celebração do IV Centenário, a se realizar no ano das eleições presidenciais e ao fim de seu mandato, seria a coroação dos projetos políticos de Carlos Lacerda. O Rio chegaria aos 400 anos de existência como uma cidade moderna e renovada para o futuro, com qualidade de vida aos moradores da cidade ao mesmo tempo em que iria impulsionar o desenvolvimento, resolvendo seus problemas crônicos, como o precário abastecimento de água e energia.

O fim do mandato de Lacerda, coincidindo com os 400 anos, era o momento propício de mostrar tanto a viabilidade do estado quanto a capacidade de gestão do governador, que aspirava à Presidência. Era preciso que a Buracap, expressão do cronista Stanislaw Ponte Preta, pseudônimo de Sérgio Porto, em referência aos buracos que atormentavam (atormentam?) os cariocas (Santos, 2013:28), se tornasse enfim a Belacap, projetada por Lacerda. O projeto era afirmar que a cidade poderia superar a perda do status de capital através de um conjunto de obras e ações que reconfigurariam a cidade e ordenariam seu espaço urbano, dotando o Rio de Janeiro da infraestrutura necessária para permitir a sua viabilidade econômica a partir de suas várias potencialidades.

Resolvida a infraestrutura, a economia carioca se desenvolveria através da realização da sua vocação industrial, com a renovação do zoneamento estabelecido pelo Código de Obras (decreto $\mathrm{n}^{0} 6.000$ de 1937). Além da busca da vocação industrial, a ser efetivada nas Zonas Norte e Oeste da cidade, a Zona Sul, como veremos, se consolidaria como área turística e de moradia para as classes mais abastadas.

\section{Formulando uma nova cidade}

O período de preparação da cidade para o seu quarto centenário foi, como citamos anteriormente, uma data comemorativa que exerceu um papel importante na reconfiguração urbana do Rio de Janeiro. O quarto centenário, em 1965, provocou um forte investimento na construção de uma nova identidade de cidade. Um leque vasto de intervenções públicas foi empreendido durante o governo Lacerda, desde a construção de um moderno sistema de abastecimento de águas até a construção de viadutos e novas vias rodoviárias. A continuação das obras do aterro com a inauguração do que hoje conhecemos como o Aterro do Flamengo, em 1965, foi, sem dúvidas, o evento mais marcante das comemorações do quarto centenário, obra que facilitou a interligação do centro com os bairros nobres da Zona Sul. Motta (2009:132) explica que, embora o Rio de Janeiro já não fosse mais a capital do país, mantinha sua natureza de vitrine do país e, como tal, precisava ser constantemente remodelada.

Motta (2009:130) sublinha, ainda, que duas intervenções urbanísticas foram sistematicamente relembradas no decorrer das comemorações do quarto centenário: o 
arrasamento do Morro do Castelo e a construção do Aterro. Esta escolha, segundo a autora, não foi aleatória, uma vez que procurava atender a dois requisitos: confrontava o coração do Rio antigo com a face da Guanabara moderna e glorificava a vitória da intervenção humana sobre a natureza, ou seja, como afirmamos anteriormente, valorizava-se a vitória da cidade sobre os obstáculos de sua geografia e história.

Consolidando-se as inúmeras intervenções estaduais, o governo da Guanabara decide, em 1964, elaborar um novo plano urbanístico para a cidade, convidando o arquiteto grego Doxiadis. O Jornal Correio da Manhã, na sua retrospectiva do ano de 1964 (1º de janeiro de 1965), sublinhou a crítica dos arquitetos de todo o Brasil "contra a decisão de Lacerda de entregar o projeto de urbanização do Rio ao grupo grego da Doxiadis”.

O plano previa uma complexa malha rodoviária para a cidade, consolidando a direção que já vinha sendo tomada pelo governo do estado. Segundo Sosa (2008:200), o plano procurava norte-americanizar a cidade, com prioridade para o automóvel. Da mesma forma, o plano sustentava uma ampla revisão do zoneamento em vigor na cidade (decreto $\mathrm{n}^{\circ} 6000$ de 1937) para que esse pudesse incorporar critérios mais modernos de planejamento previstos no plano (Sosa, 2008:206). O plano previa, ainda, um movimento de expansão urbana em direção à Barra e na industrialização da zona de Santa Cruz. Por outro lado, previa também intervenções de renovação urbana, com ênfase nos bairros de Copacabana e do Mangue.

Em relação às favelas, o Plano Doxiadis afirmou ser "indispensável que se encontrassem soluções específicas para o problema das favelas” (Cedug e Doxiadis, 1967:10). Propõe para resolver o problema, de um lado, a reurbanização e reabilitação de algumas favelas nos próprios locais que ocupavam na época, desde que não acarretasse contradições com o próprio plano e, de outro lado, a remoção de algumas favelas para áreas próximas a centros de emprego ou zonas servidas por linhas de transporte bom e barato. Esses locais deveriam ser de preferência áreas planas ou ligeiramente acidentadas ou em colinas, onde a paisagem não poderia ser desfigurada (Cedug e Doxiadis, 1967:40). A resolução da questão deveria se estender por um período longo (1966-1980). O plano afirmava, por fim, que "acreditamos firmemente que a solução do problema das favelas só pode ser alcançada na base do reconhecimento do fato de que os favelados contribuem para a vida da cidade e, assim, dentro dela devem ser acomodadas".

Apesar de anunciar que as favelas deveriam estar inseridas na cidade, o plano não critica a política de remoção, mas determina que o reassentamento pode funcionar se as novas áreas estiverem próximas onde as pessoas possam encontrar trabalho e que as "novas localizações em morros, que sejam aceitáveis do ponto de vista da preservação da paisagem, terão de ser procuradas para servirem como novos sítios para urbanização na periferia dos bairros existentes" (Cedug e Doxiadis, 1967:1071).

O Plano Doxiadis consolida, ainda, uma nova direção da política habitacional. Se a cidade do Rio ainda era uma cidade de inquilinos (Coelho apud Silva, 2012:2), a política habitacional de Lacerda e, sobretudo a empreendida pelos militares com a criação do Banco Nacional de Habitação (BNH) em 1964, deu ênfase ao acesso à propriedade privada. ${ }^{6}$ O Plano Doxiadis defendia esse novo modelo, afirmando (p. 1073) que "um homem que paga para possuir sua casa própria orgulha-se em se tornar futuramente proprietário e amadurece um senso de responsabilidade que o transforma num elemento estável na sociedade”.

6 Silva (2012:3) afirma que essa mudança foi objeto de críticas dos movimentos sociais urbanos da época, como podemos notar, por exemplo, na articulação entre as lideranças de favelas e a "Aliança de Solidariedade e Proteção aos Inquilinos", porque o número de inquilinos em favelas também era importante. 
O Correio da Manhã, de 7 de junho de 1960, afirma que havia uma "campanha permanente pelo embelezamento da cidade que deveria durar cinco anos até o quarto centenário da cidade”. A "limpeza" da Zona Sul da cidade não se limitava às favelas. Era comum encontrar acusações contra Lacerda na mídia da época por causa, por exemplo, das apreensões de mendigos. É representativo o título do Correio da Manhã, de 10 de janeiro de 1965: Mendigo não pode ver o IV Centenário. Segundo essa reportagem, a apreensão de mendigos em Copacabana, organizada pelo administrador regional do bairro, José Dias Lopes, em campanha de "saneamento" para o IV Centenário, foi amplamente criticada por personalidades cariocas, como, por exemplo, Alceu Amoroso Lima: "Vê-se turismo feito às custas de medidas arbitrárias. Não se limpa cidade para turista ver. Tudo isso é ditatorial. Não se deve fingir, mascarar, nem falsificar".

Tanto à preparação da cidade ao IV Centenário quanto os projetos elaborados por Doxiadis para a Cidade eram objeto de forte crítica quanto ao aspecto elitista de suas iniciativas. O conteúdo da reportagem do Correio da Manhã, de 16 de setembro de 1964, reafirmando indiretamente as representações sociais negativas dos subúrbios cariocas, critica as intervenções públicas previstas para o IV Centenário. Apesar de longo, é significativo para compreendermos as prioridades do governo da Guanabara:

A cidade cresce. Há muitos Cachambis. Quem tiver a coragem de fazer uma excursão turística a Madureira, Cascadura, Marechal Hermes, Bangu, Piedade, Quintino, Bocaiúva, Coelho Neto, Brás de Pina, chegará a descobrir as sete maravilhas do mundo em matéria de abandono total. Não acreditamos que o classicismo da firma Doxiadis possa transformar essa paisagem de valas pútridas em Arcádias, ou os barracões em templos gregos. Pelo menos seria esse milagre impossível até os festejos do IV Centenário. E pretende-se, porventura, mostrar aos visitantes nossos cachambis.

Da mesma forma, o governo Lacerda inaugurou a política de remoções de favelas a partir de 1962. O acirrado anticomunismo de Lacerda favoreceu muito o acesso aos empréstimos externos das agências internacionais de financiamento, o que permitiu que ele tivesse acesso a recursos oferecidos pelos norte-americanos para a política habitacional (Motta, 2000:59).

A política de remoção de favelas foi evocada muitas vezes no contexto de preparação para o IV Centenário. Em uma publicação oficial do governo do Estado da Guanabara (Secretaria de Educação e Cultura, 1965:203), valorizavam-se os novos conjuntos habitacionais: "O novo Rio orgulha-se em apresentar um aspecto que é, sem dúvida, o grande passo na melhoria das condições de habitação popular - as Vilas Esperança, Aliança, Kennedy e Cidade de Deus”. João Guimarães (1965:111), também no contexto das comemorações dos 400 anos, valoriza a política habitacional como um aspecto central na construção de uma nova cidade:

Graças ao seu atual governo do Estado da Guanabara, vão desaparecer as favelas. Muitas dessas aglomerações de barracos infectos já foram eliminados. E seus moradores alojados em conjuntos residenciais que lhes permitem higiene, comodidade, o direito de viver humanamente.

As críticas ao modo como se estavam conduzindo as remoções de favelas não tardaram. No caso da remoção da Favela do Esqueleto, o Correio da Manhã, de 6 de dezembro de 1964, relata que a FAFEG e associações de favelas da cidade se reuniram na laje do hospital das clínicas abandonado na favela do Esqueleto para lutar contra a remoção da área. Segundo o jornal, poder-se-ia aproveitar parte do terreno destinado para construir a Universidade da 
Guanabara para construir conjuntos habitacionais: "Os favelados reclamam da distância, da falta de trabalho e do fato dos preços das casas não terem preços fixos o que já está provocando despejo de favelados que para ali foram removidos (Vilas Kennedy, Aliança e Esperança)".

Apesar da resistência, a Favela do Esqueleto foi finalmente removida em 1965. No entanto, o caso de Brás-de-Pina - o mais paradigmático de resistência às remoções - se materializou como a grande derrota política de Lacerda. Diante da forte resistência dos moradores, com auxílio da Igreja através da luta do padre espanhol Jose Sanz Artola, o governo do Estado foi obrigado a ceder. Apesar de longo, parece-nos importante transcrever o editorial do Correio da Manhã, de 3 de janeiro de 1965:

\footnotetext{
Ontem, na Guanabara, a democracia teve talvez sua mais importante vitória neste país desde o dia $1^{\circ}$ de abril do ano passado. O governador Carlos Lacerda recebeu o vigário de Brás de Pina, padre Jose Sanz Artola, e entregou os pontos: só sairão de Brás de Pina os favelados que desejarem mudar-se para as casas construídas pela COHAB. Ninguém será removido à força. (...) Ninguém, em nenhum lugar do mundo, pode ser contra a ideia de extinguir favelas, no sentido de acabar com uma miséria tão extrema que leva seres humanos a viverem em agrupamentos miseráveis de casebres. O perigoso, o que define toda a linha política de um governo, é confundir o horror à favela com o horror ao favelado. Construir casas habitáveis para os que ora vivem em favelas não é assunto que exija debate. Mas levar à força para essas casas muitos dos que não poderão pagar o aluguel cobrado, ou que perderão o emprego que têm, sem que outro lhes seja oferecido, pode ser um serviço prestado à higiene ou à paisagem, mas é um inominável crime perpetrado contra a criatura humana.
}

Os resultados da política de Lacerda se fizeram sentir nas eleições de 1965. Apesar das inúmeras obras realizadas e das comemorações pelos 400 anos, Lacerda sofreu uma grande derrota nas eleições de outubro. Como sublinha Motta (2000:95), a esmagadora vitória de Negão de Lima sobre o candidato de Lacerda, Flexa Ribeiro, sobretudo da "Praça da Bandeira pra lá”, indica quem foi mais beneficiado pelo governo de Lacerda.

No que concerne à política de remoção de favelas, o paralelo com os dias atuais é patente (Brum, 2013). Num relatório de monitoramento das ações da Secretaria Municipal de Habitação feito em 2009 pelo Tribunal de Contas do Município, logo em sua Introdução são apresentados alguns argumentos que foram largamente usados como pilares para sustentar a defesa da remoção nas décadas de 1980 a 2000, período em que as remoções arrefeceram: a questão ambiental, a questão da violência urbana e, finalmente, a preparação da cidade para os Grandes Eventos:

\footnotetext{
A discussão em torno das favelas vem tomando enormes proporções e demandando soluções urgentes, seja pela necessidade de se restaurar áreas legalmente preservadas e degradadas por um excessivo desmatamento, seja pela crescente violência a que essas localidades estão sujeitas em razão do difícil acesso do Poder Público ou pela adequação às exigências do Plano Olímpico para as Olimpíadas de 2016. (Tribunal de Contas do Município do Rio de Janeiro, 2009:6)
}

Nas considerações finais do relatório, a postura do governo municipal é elogiada como corajosa:

\footnotetext{
A política de não remoção começa a deixar de ser um tabu, sendo repensada em benefício da Cidade como um todo, haja vista as ações previstas nos projetos relacionados à Copa do Mundo de 2014 e às Olimpíadas de 2016. (Idem, p. 34)
}

Assim, o Poder Executivo municipal, em seu Plano Plurianual 2010/2013, apresentou, em linguagem altamente técnica, o Programa 0321 - Urbanização de assentamentos precários (Incluindo como ações conjuntas o PAC - Urbanização, Urbanização de Assentamentos informais e Plano Municipal de Habitação de Interesse Social); cujo objetivo geral é: 
promover a melhoria das condições de habitabilidade nos assentamentos precários, com impacto na redução da incidência e do desordenamento dos assentamentos subnormais, por meio da urbanização, regularização urbanística e fundiária, inclusão produtiva e social e sustentabilidade ambiental. (Prefeitura da Cidade do Rio de Janeiro, 2009:23)

Embora o plano não traga uma orientação clara sobre seus objetivos, e as ações anunciadas lidas em conjunto indiquem o viés de realocação de moradores, com o Plano Munici

pal de Habitação de Interesse Social, a meta, segundo a Secretaria Municipal de Habitação, era reduzir em $5 \%$ o total da área ocupada por favelas. ${ }^{7}$

O plano Estratégico da Cidade do Rio de Janeiro, de 2009, estipulou ainda que seria necessário “coibir novas ocupações ilegais e a expansão horizontal ou vertical das comunidades estabelecidas, a partir do uso efetivo de ecolimites e de um monitoramento aerofotográfico constante". ${ }^{8}$ O plano previa, ainda, a redução de 3,5\% das áreas ocupadas por favelas na cidade até $2012 .{ }^{9}$ Segundo o jornal $O$ Globo, de 14 de setembro de 2009, tal redução seria aplicada a partir de três medidas: i) a construção de 50 mil casas populares, que seriam oferecidas aos moradores de baixa renda, ii) a transferência das famílias que hoje moram em áreas de risco, e, por fim, iii) a urbanização das favelas. Essa meta foi alçada para 5\% no novo plano estratégico de 2013 e deve ser alcançada, segundo esse plano, até 2016 . $^{10}$

O trecho abaixo do jornal $O$ Globo, de 13 de outubro de 2011, relaciona as remoções com a necessidade de preparação da cidade:

\begin{abstract}
São injustificáveis, inclusive do ponto de vista humorístico, tentativas de conhecidos personagens da vida política de evitar a retirada de famílias de áreas de risco, como tem feito a prefeitura como medida preventiva contra tragédias. E é de se prever que do mesmo front populista partam missões para solapar a recente decisão do município de remover famílias que ocupam, a maioria delas irregularmente, áreas cuja reurbanização é inegociável entre as ações para adaptar o Rio aos compromissos assumidos para sediar jogos da Copa do Mundo e as Olimpíadas.
\end{abstract}

Como anunciou o jornal $O$ Globo de 8 de janeiro de 2010: "Desmistifica-se, afinal, o termo 'remoção', para o bem de todos os cariocas”. As remoções se justificaram em alguns casos por causa das obras de infraestrutura. A construção da linha de ônibus articulado, Transoeste, removeu um número importante de casas, sobretudo em favelas, sem que se tenha demonstrado efetivamente a necessidade da retirada das construções. O jornal O Dia, de 18 de setembro de 2013, afirmou que o número de remoções, não somente em favelas, para a instalação da linha segregada de ônibus articulado Transcarioca, ligando o aeroporto à Barra, caiu de 3600 previstas inicialmente para 1793. Segundo a mesma reportagem, o planejamento foi feito com base no Google Maps e as informações não coincidiram com a realidade. Segundo uma fonte da Secretaria Municipal de Obras que não quis ter seu nome revelado: "Não havia necessidade de desapropriar muita coisa que já foi colocada no chão. Agora é tarde".

A questão do risco ambiental também foi amplamente evocada, sobretudo em períodos de grandes chuvas. Em abril de 2010, por exemplo, quando a cidade atingiu a marca recorde

$7 \mathrm{SMH} /$ Prefeitura da Cidade do Rio de Janeiro. Habitação em Foco -ano 1 - nº 2- 2010.

8 Plano estratégico da Prefeitura do Rio de Janeiro 2009-2012. Pós 2016: 0 Rio mais integrado e competitivo, Rio de Janeiro: Prefeitura do Rio de Janeiro, 2009, p.31.

9 Plano estratégico da Prefeitura do Rio de Janeiro 2009-2012. Pós 2016...Op. Cit. p.46.

10 Plano Estratégico da Cidade do Rio de Janeiro. 2016. Um Rio mais integrado e competitivo, 2013, p.55 in http://www.conselhodacidade.com/v3/ pdf/planejamento_estrategico_13-16.pdf 
de índice pluviométrico de 288,4 mm em 24 horas (06 a 07/04), as obras de contenção de encostas e urbanização de favelas realizadas por diversos governos nas décadas anteriores foram duramente criticadas por vários atores por 'manterem as favelas', como vemos na capa da Revista Veja de 10/04/2010. Sobre uma imagem de um Cristo Redentor em lágrimas, lêse a seguinte legenda: "Culpar as chuvas é demagogia. Os mortos no Rio de Janeiro que o Brasil chora foram vítimas da política criminosa de dar barracos em troca de votos”. Na parte interna da revista lê-se: "Rio... Do descaso, da demagogia, do populismo e das vítimas de suas águas. A maior tempestade da história do Estado causa centenas de mortes nas favelas e expõe o lado sombrio da política de incentivos à ocupação ilegal de áreas de risco nos morros".

Em outro viés, a questão ambiental juntava-se à desvalorização imobiliária de áreas vizinhas à favela. Assim, na década de 1990, o Programa Favela Bairro encontrou resistências de moradores das classes média e alta no bairro do Recreio dos Bandeirantes, como mostra matéria do Jornal do Brasil de 01/08/1996 "Favela-Bairro gera reclamações no Recreio":

\footnotetext{
"O Conselho Comunitário do Recreio acusa a prefeitura de desrespeitar o Plano Lúcio Costa ao erguer um conjunto popular em uma área de preservação ambiental.” - declaração da presidente do Conselho Comunitário: (...) "Essa proposta é incoerente. De um lado da rua eles fazem um programa social construindo uma favela urbanizada para pessoas de baixa renda. Do outro lado da rua, os moradores, que já tinham suas casas, são obrigados a pagar um IPTU que varia de R\$ 2 a R\$ 3 mil”.
}

Nesse sentido, a questão ambiental foi amplamente expressa também no Plano Estratégico da Cidade do Rio de Janeiro (2013:89), que afirmou que entre 1984 e 2001 houve uma drástica redução de 17\% da cobertura vegetal nativa do Rio de Janeiro, principalmente devido à expansão de favelas na Área de Planejamento 4 (AP4) e na AP5. A relação entre favelas e destruição do meio-ambiente é novamente anunciada (2013:82): "A expansão da área de favelas da cidade se deu em grande medida a partir do desmatamento de áreas verdes que deveriam ter sido preservadas".

Da mesma forma, as próprias intervenções de urbanização de favelas pressupunham a remoção de um grande número de casas. Da mesma forma, a instalação das unidades de polícia pacificadora (UPPs) reforçou o processo de encarecimento de vida nas favelas e permitiu um maior controle da prefeitura sobre novas construções. Ao invés de construir de forma participativa uma legislação urbanística local, que respeite os limites e as possibilidades de novas construções nas favelas, a prefeitura, através do decreto $\mathrm{n}^{0} 33.648$ de 11 de abril de 2011, estabeleceu uma espécie de congelamento urbanístico das favelas (Gonçalves, 2012):

\footnotetext{
Fica vedado iniciar a construção de novas edificações em favelas declaradas por Lei como Áreas de Especial Interesse Social - AEIS. Parágrafo único. Excetuam-se as construções de iniciativa e responsabilidade do Poder Público destinadas ao reassentamento de população situada em áreas de risco, de preservação ambiental e em áreas objeto de projeto de urbanização da comunidade, que poderão ser licenciadas observando os Decretos específicos.
}

Em uma reportagem do jornal O Globo, de 22 de novembro de 2011, a prefeitura anunciava que aumentaria de dois para 20 o número de fiscais para fazer cumprir a lei. $\mathrm{Na}$ mesma reportagem, o administrador regional da Rocinha, Jorge Collares, afirmou que

O prefeito Eduardo Paes, que esteve na comunidade na semana passada, determinou que sejamos rigorosos. Só vamos permitir que construam casas para uma família. Mesmo assim elas não poderão estar sobre valas, em áreas de proteção ou em locais de risco. Tudo o que estiver em desacordo com o decreto de abril será demolido. 
No entanto, se esse decreto foi parcialmente imposto a algumas favelas da cidade, inclusive com a destruição midiática de novas construções, não parece que suas determinações sejam aplicadas em certas favelas que conhecem um processo de gentificação, como o Vidigal, por exemplo. Segundo a Revista O Globo, de 19 de maio de 2013, as normas de ocupação foram criadas para impedir o crescimento desenfreado das favelas, "mas não regulam a chegada de novos moradores e empresários nem ajudam a fixar os antigos. Ou seja: não preveem o futuro". O mesmo jornal crítico contundente à presença das favelas na cidade, cita, paradoxalmente, as palavras do arquiteto Maurício Nóbrega sobre a arquitetura típica das favelas, que outrora abominada pela cidade, é agora valorizada no Vidigal, tornandose "um desafio para os donos de pranchetas, que precisam lidar com espaços diminutos, distâncias e ventilações mínimas entre as casas, além de dificuldade de acesso".

Ainda que por vezes adotando uma posição crítica às experiências anteriores, nos dias atuais assistimos ao retorno da palavra remoção com referências aos processos da década de 1960, conforme demonstra, por exemplo, a reportagem do jornal O Globo, de 13 de dezembro de 2011:

Em razão de resultados negativos advindos de mal planejadas iniciativas de relocação de famílias na década de 60, críticas populistas ao reassentamento tiveram o dom de, por muitos anos, tornar essa imperiosa solução um tabu nos programas governamentais. Mas, enfim, de alguns anos para cá, o poder público tem se curvado aos interesses maiores do desenvolvimento urbanístico, e voltou a incluir tal medida no manual da administração.

Observa-se o prosseguimento da mesma divisão espacial projetada pelo governo Lacerda e pelo plano urbanístico de Doxiadis atualmente, conforme demonstram as palavras do jornalista Ali Kamel. Ainda no início das grandes obras que estão varrendo a cidade, o jornalista sustentou que os pobres deveriam morar com "dignidade” nos subúrbios, longe, mas há poucos minutos, das áreas ricas da cidade:

\footnotetext{
Quando isso estivesse feito, quando os subúrbios estivessem a poucos minutos das áreas ricas do Rio de Janeiro (como ocorre nas grandes capitais do mundo), a remoção de favelas inviáveis deixaria de ser um palavaão: morros inabitáveis deixaria de ser um palavrão: morros inabitáveis, como Dona Marta, Pavão, Pavãozinho, Cantagalo, Vidigal, parte da Rocinha, parte do Alemão, para citar apenas alguns poucos, poderiam ter as suas populações realocadas em bairros decentes, com transporte bom e barato. Trocariam uma casa dependurada numa ribanceira, cercada por becos impossíveis de ser urbanizados, por bairros populares decentes e de fácil acesso. (O Globo, 7 de abril de 2009)
}

Assim, conforme apontamos no início deste artigo, o passado surge como obstáculo a ser superado dentro das novas configuração e função da cidade. As favelas que se consolidaram em espaços (até pouco tempo) em declínio da cidade, caso da Providência no Centro, ou nas bordas da expansão urbana, caso das localizadas na Baixada de Jacarepaguá, são alvo preferencial da atual voga remocionista, em que os terrenos por elas ocupados darão lugar a novas funções: vias, equipamentos urbanos, equipamentos olímpicos ou, ainda, embora isso não seja dito abertamente, novos empreendimentos imobiliários. ${ }^{11}$

O passado também é superado nas novas funções que as favelas podem adquirir na nova etapa da cidade. Assim, se de um lado existem favelas que devem ser removidas, de outro, através de ações do Estado, e de outros agentes, elas podem se tornar uma excelente oportunidade de negócios.

110 caso da Favela Vila Recreio 2 é emblemático quanto à incerteza de qual será 0 uso do terreno das favelas removidas. Tendo sido removida totalmente para dar passagem à duplicação da Avenida das Américas e 0 corredor Transoeste do BRT, as pistas acabaram ocupando somente um pequeno trecho da antiga favela, estando o terreno vazio em sua maior parte, nAuma área que vem passando por intensa valorização imobiliária (Famílias removidas de áreas onde nada foi feito, 0 Dia, 06/09/2013). 
Em primeiro lugar, a instalação de unidades de polícia pacificadora (UPPs) trouxe fortes impactos econômicos nas adjacências das favelas ocupadas. Segundo Nelson Freitas, diretor regional da Júlio Bogoricin Imóveis, o mercado imobiliário em Botafogo sofreu um forte aquecimento logo após a ocupação da favela de Santa Marta: "As ruas da Matriz e das Palmeiras, que sofriam muito com a proximidade da favela por causa de tiroteios e assaltos, não têm mais esses problemas. Espero que o governo faça a mesma coisa na Rocinha" $(O$ Globo, 21/12/2008).

Para o comércio varejista, as UPPs se constituíram numa importante oportunidade tanto de 'recuperar' pontos no asfalto, quanto de conseguir novos clientes nas favelas (Burgos et al, 2013). Estamos falando da incorporação à economia formal e aos agentes econômicos que nela atuam de um mercado, em ascensão, que em 2008 movimentou mais de 3 bilhões de reais. ${ }^{12}$

O jornal O Valor, de 23 de novembro de 2011, relata o interesse de um empresário de uma grande rede varejista em investir em favelas pacificadas: "A nossa maior dificuldade é a formalização dos imóveis, porque normalmente são áreas invadidas, aí fica mais difícil”. Ora, se a presença da polícia permitiu um boom econômico, entendemos que a regularização fundiária através da distribuição massiva de títulos pode reforçar o processo de gentrificação em algumas favelas. O presidente da Associação Comercial do Rio e da Light, Jose Luiz Alguéres, estimou, em 2009, por exemplo, que o PIB da cidade poderia crescer de $20 \%$ a $30 \%$ com a instalação das UPPs. Ele defende a retomada de medidas de distribuição de títulos nas favelas, tendo como ponto principal para justificá-la a valorização imobiliária nessas áreas:

Para isso, é preciso vencer os desafios de dar a todas as favelas a titularidade dos imóveis e infraestrutura social e urbana, incluindo segurança. A questão da titularidade tem que ser encarada de frente. Se o valor dos imóveis já triplicou nas comunidades com UPPs, imagina como isso ficaria com a titularidade? (O Globo, 16/08/2009)

Os resultados da incorporação de territórios da cidade à economia formal através das UPPs já são significativos para grandes agentes de mercado. Um exemplo disso é a Light, empresa de energia elétrica, que tem alcançado índices de mais de 90\% de rede formal nas favelas com UPP. No caso do Santa Marta, a arrecadação da empresa nessa comunidade cresceu $5437 \%$ com a implantação da UPP. ${ }^{13}$

A pacificação de favelas também trouxe a possibilidade de retomada das atividades industriais em áreas da cidade atingidas pela violência. Como veremos no próximo item, a interpenetração das favelas e da política habitacional industrial e habitacional era extremamente importante no contexto do IV Centenário e parece se manifestar, em menor escala, também nos dias atuais. Segundo o diretor executivo da Associação Comercial e Industrial de Jacarepaguá (ACIJA), Aluízo Cunha, as indústrias estão mapeando as vagas existentes para usar a mão de obra da Cidade de Deus (O Globo, 12/08/2009).

\section{Rio de Janeiro: a utopia industrial}

As duas conjunturas em que se dão os marcos de comemoração dos 400 e dos 450 anos apresentam similaridades também na forte articulação dos projetos locais da cidade com

12 Comércio na favela fatura $\mathrm{R} \$ 3$ bi por ano, 0 Globo, 24/08/2008.

13 Light já reduziu em 90\% 'gatos' de energia em cinco comunidades com UPPs, 0 Globo, 03/01/2012.

48 - Cadernos do Desenvolvimento Fluminense, Rio de Janeiro, N.7, pp. 37 - 56, jan./jun. 2015 
o projeto nacional, a despeito das delicadas relações políticas que pudesse existir entre o político que ocupe o Executivo local e o governo federal.

Tanto num período como no outro, os rumos da política macroeconômica em nível nacional interferiram diretamente nas decisões locais. Assim, se Eduardo Paes foi um opositor ferrenho quando deputado federal durante o primeiro governo do Partido dos Trabalhadores (PT) com Lula na Presidência, modificou sua postura quando se candidatou a prefeito em 2008 (e novamente em 2012), ${ }^{14}$ viabilizando alguns diretrizes e/ou programas dos governos encabeçados pelo PT, como o Programa de Aceleração do Crescimento (PAC) e a própria realização dos Grandes Eventos, como os Jogos Olímpicos de 2016 que projetam não só a imagem da cidade do Rio, mas a do Brasil. Por isso, conta com pesados investimentos públicos e privados em obras de infraestrutura que, se por um lado geram empregos e impulsionam a economia, por outro são repletas de críticas aos grandes lucros das empreiteiras responsáveis pelas obras bem como pelos custos sociais como as remoções de comunidades (abordaremos esse ponto mais à frente). ${ }^{15}$

Do mesmo modo, embora Carlos Lacerda fizesse um discurso fortemente oposicionista aos governos do Partido Democrático Brasileiro (PTB) e Partido Social Democrático (PSD) na esfera federal, na Guanabara ele baseou suas decisões quanto aos rumos do estado em modelo similar aos pressupostos da política desenvolvimentista cepalina (Prebisch, 2000), com forte apoio à industrialização como modo de desenvolvimento econômico considerando que, embora declinante, a Guanabara ainda continha o segundo maior parque industrial do país.

Lacerda também fez a opção pelo transporte rodoviário como principal modal de transporte, além de várias de suas principais obras serem de ampliação e de melhorias da malha rodoviária do Rio, na esteira da ampliação da indústria automobilística feita por Juscelino Kubistchek. Os bondes, antigos componentes da paisagem urbana do Rio e que foram vetores da própria expansão da cidade (Abreu, 1997:25), cederam lugar aos ônibus, que se tornaram o principal meio de transporte da cidade, com mais de 1 bilhão e 200 milhões de passageiros por ano, contra 187 milhões do segundo modal (metrô), segundo dados de $2012 .{ }^{16}$

Vale dizer que a vocação industrial não foi objetivo apenas do governo Carlos Lacerda. Os governos estaduais posteriores também, inclusive os municipais a partir da Fusão com o Estado do Rio em 1975, mantiveram essa diretriz da opção da indústria como eixo de desenvolvimento econômico, percepção que a perda da função administrativa ampliou entre políticos e empresários, assim como a prioridade dada a automóveis e ônibus na cidade continua sendo marca de todos os governos após Lacerda, e ainda hoje.

14 Eduardo Paes começou sua carreira no Partido Verde, sendo subprefeito da Barra e Jacarepaguá no primeiro mandato de Cesar Maia na Prefeitura do Rio, ocupando outros cargos por outros partidos até se tornar deputado federal em 1998 pelo PFL (Partido da Frente Liberal, atual Democratas) e ser reeleito em 2002, quando migrou para o PSDB (Partido Social Democrata Brasileiro e, desde 2003, principal partido de oposição ao governo do PT) no ano seguinte. Tendo um mandato com fortes críticas ao governo do presidente Lula, Eduardo Paes se elegeu e reelegeu prefeito do Rio de Janeiro em 2008 e 2012, respectivamente, quando agradeceu a Lula e Dilma, nessa última ocasião e "Depois dos cariocas, que nos deram essa confiança mais uma vez, eu queria agradecer a dois personagens políticos, duas figuras que foram muito inspiradoras ao longo desses quatro anos (...) eu queria agradecer a esses dois presidentes da República, Dilma e Lula, pelo carinho, pela dedicação, pelo amor ao Rio de Janeiro e pela confiança ao nosso trabalho aqui. Dizer que nós vamos continuar trabalhando juntos pelos próximos quatro anos" (Eduardo Paes agradece a Lula e Dilma a reeleição no Rio, http://www.cartamaior.com.br/?/Editoria/Politica/Eduardo-Paes-agradece-a-Lula-e-Dilma-a-reeleicao-no-Rio\%0D\%0A/4/25823 consultado em 12/06/2014).

15 Uma visão crítica acerca do atual ciclo 'neodesenvolvimentista' (relativizando o próprio termo) no país e sua relação com as políticas urbanas encontra-se em Maricato (2013)

16 Movimento de passageiros de transportes rodoviário, ferroviário, hidroviário e aeroviário -1995-2012. Ver http://portalgeo.rio.rj.gov.br/indice/ flanali.asp?codpal=296\&pal=TRANSPORTE. Consultado em 20/06/2014. 
No entanto, segundo estudo do economista Mauro Osório, a cidade do Rio tinha sua participação na produção industrial brasileira declinante desde a década de 1930 (Osório, 2005). Embora o fato não fosse desconhecido das autoridades e empresários da época, outras razões eram atribuídas a ele. Como a participação do antigo Estado do Rio na indústria era crescente, a visão predominante na época era de que a cidade sofria um 'esvaziamento' econômico, perdendo indústrias para o Estado do Rio, devendo resolver, então, questões como infraestrutura e zoneamento urbano a fim de tornar-se novamente polo de atração de fábricas.

Solucionar problemas da infraestrutura urbana tornara-se necessidade premente. $\mathrm{O}$ abastecimento de água, além de insuficiente, era feito por um sistema que foi construído em épocas diferentes e de formas diferentes, sendo uma verdadeira colcha de retalhos, além de necessitar de amplas reformas pelo desgaste natural. Em 1961, por exemplo, o sistema ficou paralisado devido a fortes chuvas que queimaram as bombas, deixando a população do recém-criado Estado da Guanabara sem água por duas semanas (Companhia Estadual de Águas e Esgotos, 2007:15).

Lacerda tomou como uma das principais metas de seu governo fazer um sistema que abastecesse a cidade satisfatoriamente até o ano 2000. Para isso, tomou empréstimos do Banco Interamericano de Desenvolvimento e criou a CEDAG, Companhia Estadual de Águas da Guanabara, atual CEDAE, que fez uma ampla reforma dos encanamentos, reservatórios e elevatórias. Além disso, iniciou a construção da terceira, e maior, adutora do Guandu, através de escavações na rocha que fizeram um túnel-canal do Guandu, levando água até o Jardim Botânico, na Zona Sul do Rio, no Reservatório dos Macacos, e liga-se aos outros dois sistemas através de sub-adutoras. Tendo sido inaugurada três meses após o fim do mandato de Lacerda, a nova adutora do Guandu aumentou a capacidade do sistema em 2,4 bilhões de litros por dia, tendo escavado, no total, 43 quilômetros de rocha. Embora tenha dobrado a capacidade de abastecimento da cidade-estado, posteriormente o sistema precisou passar por três obras de ampliação, antes de atingir o ano 2000. E ainda hoje é responsável pela maior parte do abastecimento de água da cidade e da Região Metropolitana do Rio de Janeiro (Companhia Estadual de Águas e Esgotos, 2007:28).

No abastecimento de energia, o Rio de Janeiro tinha dois entraves graves: a diferença de frequência entre o Rio (50 hz) e outras regiões do país, como São Paulo (60 hz) impedia a utilização das novas usinas geradoras. Além disso, a produção local de energia mantinha-se a mesma desde 1945, o que ocasionava apagões, havendo inclusive racionamento de energia entre 1963 e 1964. A política energética do governo Lacerda, embora tenham sido aventadas várias medidas, não logrou mudar o quadro (Perez, 2007:218)

De qualquer forma, a implantação de zonas industriais se daria em paralelo à resolução dos problemas da infraestrutura urbana, servindo ao mesmo tempo para assegurar às fábricas uma melhor distribuição de água e energia, além de providenciar um melhor fornecimento para áreas centrais da cidade, principalmente para uma Zona Sul não saturada com fábricas.

A necessidade de reordenar o espaço urbano, vinculando o reposicionamento das indústrias e dos favelados como mola-mestra deste projeto, tem defensores desde o fim da década de 1940.

No Censo das Favelas de 1949, da Prefeitura do Distrito Federal, é apontado que, entre os moradores da favela empregados, 50,5\% eram trabalhadores de indústrias. Nesse documento, é analisada a relação entre o mercado de trabalho e a procura de moradia próxima, em que o custo de transporte e o tempo gasto nele por parte dos trabalhadores são tidos como um 
dos problemas que geram a formação de favelas, particularmente na Zona Sul, área em que o mercado de trabalho para os favelados é constituído por empregos em serviços e comércio; para o caso da Zona Norte, a explicação para as favelas se dá pelo fato de que as indústrias se concentram nessa região, mas "a ampliação delas resultou em necessidade de mão de obra, sem que paralelamente fossem tomadas providências para alojar o consequente aumento de operários" concluindo então que "a solução encontrada, em qualquer dos casos, foi a favela" (Prefeitura do Distrito Federal, 1949:6).

O Censo apresenta ainda como uma das medidas positivas a construção de residências 'de preço acessível' próximo às fábricas, como foi o caso de Bangu, enquanto lamentava a localização de uma vila proletária em Marechal Hermes, que se tornara uma 'decepção', por ser moradia de poucos operários, distante que estava de locais de trabalho para estes.

Maria Laís Pereira da Silva aponta também que, na década de 1950, o deslocamento das indústrias se tornava mais imperativo por imposições decorrentes da forma de desenvolvimento urbano da cidade, com a inexistência de terrenos amplos nas áreas mais centrais, bem como a valorização excessiva destes ou, ainda, a falta de uma infraestrutura, como no saneamento, por exemplo. Também a infraestrutura da cidade como um todo passava por grave crise, com panes no abastecimento de água e energia, o que demandava o deslocamento das indústrias para locais mais distantes destas áreas centrais onde antes se implantavam (Silva, 2005:34).

Por sua vez, no Relatório SAGMACS (1960:39), ${ }^{17}$ publicado em 1960, constava:

\footnotetext{
É imperativo que a implantação da indústria se faça de maneira mais racional, destinando-se às fábricas uma localização mais adequada. A construção das fábricas nem sempre inclui moradia para os operários. (...) A concentração da indústria em determinada área e a construção de bairros operários, financiados pelos institutos interessados e pelos próprios industriais, facilitaria a solução do problema.
}

As linhas gerais para o zoneamento urbano, definidas por Carlos Lacerda ao longo de seu governo e consolidadas no Plano Doxiadis, entregue no último ano de seu governo, com as obras (vias, túneis, viadutos, conjuntos habitacionais) já em execução ou em conclusão, previam o deslocamento da área industrial do Rio para áreas nas zonas Norte e Oeste, em direção ao Porto de Sepetiba, ligando as áreas da cidade através de um sistema rodoviário com vários túneis e as linhas policromáticas (Vermelha, Amarela, etc.), sendo a Avenida Brasil um dos eixos principais, onde se instalariam bairros-proletários (Rezende, 1982:32). Segundo a arquiteta Maria Laís Pereira da Silva, "na primeira metade da década de 1960, a questão industrial mereceu uma ação combinada com a habitação” (Silva, 2005:22).

A ideia da instalação de conjuntos habitacionais nos subúrbios do Rio também figurava no caput do Decreto n. 793, de 29/12/1961, do Governo da Guanabara, ao definir a Zona Industrial das Bandeiras (em referência à Av. das Bandeiras, antigo nome da Av. Brasil a partir da rodovia Washington Luís): "É necessário definir zonas industriais para a expansão das fábricas, o estabelecimento de condições de habitação dos trabalhadores, e outros requisitos, para definir a primeira delas" (IDEG, 1968:4).

A interpenetração entre indústria e habitação também se manifestou nas políticas públicas em relação às favelas. Segundo o relatório do IDEG (1968:28), a ocorrência de favelas nas áreas de maior concentração industrial encerraria aspecto benéfico para a atividade

17 SAGMACS (Sociedade de Análises Gráficas e Mecanográficas Aplicadas aos Complexos Sociais). Estudo, coordenado por José Artur Rios, de vários aspectos das doze maiores favelas do Rio. A ideia inicial de transformar o relatório em livro não se concretizou, saindo na forma de dois suplementos no Estado de São Paulo em abril de 1960 com o nome de Aspectos Humanos da Favela Carioca. 
industrial, que "pode ser traduzido pela possibilidade de captação de mão de obra em locais próximos às fábricas”. O relatório IDEG afirma, ainda, que, no caso de indústrias que sofrem efeitos sazonais, a relativa proximidade de uma favela se reveste de características extremamente favoráveis, pelas possibilidades que oferece para uma rápida arregimentação de pessoal, quando há necessidade de se intensificar o trabalho. O texto, finalmente, conclui (p. 31): "Conforme revelam os resultados da pesquisa, a superposição das áreas faveladas às regiões de grande concentração industrial do Estado da Guanabara não chega a se constituir para a atividade manufatureira em um embaraço de grandes proporções”.

Um dos fundamentos dessa política foi a criação, em 1961, da Companhia de Progresso da Guanabara (Perez, 2007:216), que deveria arregimentar interessados, financiar empreendimentos, além de coordenar toda a política industrial. Deste modo, a Copeg adquiriu dois lotes: um na Avenida Brasil, na divisa com o Estado do Rio e a Baixada Fluminense, em meio às principais rodovias (Presidente Dutra e Washington Luís) e outro em Santa Cruz, para torná-los distritos industriais.

A localização desses dois empreendimentos seguia as diretrizes que se consolidariam no Plano Doxiadis. Duas vias cortariam a Guanabara diametralmente: a Avenida Brasil, ao norte, e a Avenida das Américas ao sul, que se ligaria ainda à Lagoa Barra até o Túnel Rebouças, fechando o circuito à leste, e à oeste as duas vias se encontrariam. A Avenida Brasil seria a via de integração econômica por excelência, ligando-se às rodovias que trariam insumos e levariam mercadorias a outras regiões do país e aos portos do Rio e de Sepetiba (hoje Itaguaí) cruzando toda uma região industrial que contaria com conjuntos habitacionais em que moraria a mão de obra dessa indústria.

Para tornar isso possível, Lacerda criou, em 1962, a Companhia Estadual de Habitação (COHAB) com a qual rompia com a postura anterior de seu governo em que a urbanização de favelas era a tônica (Valla, 1986:76-84). Desde seus primeiros meses de existência, a COHAB encarava que a solução possível para o problema favela era a remoção. Um documento produzido nos primeiros meses da Cohab:

\footnotetext{
Depois de 1955, o Estado voltou seus olhos mais uma vez para o problema. Criou vários órgãos e instituições que tentaram por várias formas e meios minimizar os efeitos das pressões socioeconômicas que atuaram sobre a população favelada. Nenhum deles tinha como objetivo a erradicação dessas aglomerações. $\mathrm{O}$ atual governo [Lacerda] foi o primeiro a enfrentar o problema em termos de erradicação. (Relatório Geral 1963-1965. Cohab, apud Leeds e Leeds, 1978:115)
}

A COHAB contou com recursos vindos do Fundo do Trigo, acordo firmado entre o governo da Guanabara e a Usaid (agência de desenvolvimento externo norte-americana) como parte do programa Aliança para o Progresso, programa de cooperação internacional entre os Estados Unidos e a América Latina, criado pelo governo Kennedy em 1961, como forma de combater a influência da Revolução Cubana e também melhorar a imagem dos Estados Unidos no continente, seriamente desgastada nessa época (Perez, 2007:120-2).

O acordo consistia em recursos vindos da compra de trigo dos Estados Unidos pelo Brasil que eram emprestados para serem reaplicados em projetos de desenvolvimento. No governo Lacerda, os recursos da Aliança Para o Progresso foram utilizados nas remoções e na construção dos conjuntos que abrigariam os removidos: Vila Esperança, Vila Aliança, Vila Kennedy e Cidade de Deus (apenas iniciada a construção). Os três últimos se localizam na Zona Oeste do Rio de Janeiro, a algumas dezenas de quilômetros das favelas de onde viriam os removidos. 
As primeiras remoções estavam ligadas às áreas onde estavam previstas as obras, como favelas na Avenida Brasil, para construção do Mercado São Sebastião ou a Favela do Esqueleto, para construção da Avenida Radial Oeste e da Universidade da Guanabara (hoje UERJ). Em seguida, dentro do plano de reordenamento urbano do Rio de Janeiro, as remoções de favelas se deram em terrenos na Zona Sul, de alto valor imobiliário e destinada a ser uma área residencial para classes de maior poder aquisitivo.

\section{Conclusão}

Às vésperas do IV Centenário, a política de segregação espacial da cidade tomava proporções inéditas, com os favelados sendo expulsos das áreas centrais da cidade, particularmente na valorizada Zona Sul, transferidos para terrenos vazios na periferia, a algumas dezenas de quilômetros do centro da cidade e de seus antigos empregos.

Se as favelas haviam servido para alimentar a expansão urbana na Zona Sul, abastecendo-a de mão de obra para a construção civil e para serviços de baixa qualificação, o viés que o surgimento de favelas na Zona Norte do Rio, em busca de empregos na indústria, representava (no que as favelas da Tijuca e o Jacarezinho são casos paradigmáticos) será utilizado pelo Estado no conjunto de reformas que a cidade viveu entre a perda da função de capital da República e o IV Centenário (e além, na verdade, com obras que só seriam terminadas ou executadas depois).

Para os mais pobres, a nova função da cidade significou remoções e novas funções para as favelas na cidade. Assim, além de dotar o Estado de infraestrutura (o que não significou que a distribuição fosse igualitária ou mesmo integral para todo o território), o ponto-chave das reformas urbanas ocorridas no governo de Lacerda era reordenar o espaço urbano do Rio de Janeiro por dois vieses: nas zonas Norte (principalmente) e Oeste da Guanabara um conjunto de obras dotaria o subúrbio de mobilidade e de condições de abrigar a mão de obra fabril que residiria perto do emprego; na Zona Sul, a região consolidaria seu papel turístico por meio de obras de embelezamento, do qual a remoção de favelas seria peça-chave. Por último, a ligação entre as diversas regiões da cidade por vias expressas que integrariam essas diversas funções e apontariam os rumos da expansão.

Em todas essas ações vemos os dois traços citados acima, da expansão urbana da cidade vencendo a geografia e o passado da cidade. Túneis cortaram montanhas, o mar que tocava a antiga Zona Sul foi aterrado, favelas de décadas de existência foram removidas para dar espaço a vias expressas ou simplesmente para que o local fosse 'embelezado'.

O volume de obras nos dias atuais é comparável ao do passado. As novas vias expressas, que cortam a cidade com os BRTs, com suas pontes estaiadas e túneis, reconfiguram a geografia da cidade, encurtando distâncias e consolidando, mais uma vez, os interesses dos empresários de ônibus da cidade. Além dos investimentos na prolongação do metrô em direção à Barra da Tijuca, iniciam-se, também, as obras de duplicação do elevado do Joá, consolidando o modal rodoviário e privilegiando o fluxo Zona Sul-Barra da Tijuca.

Da mesma forma, o patrimônio e a paisagem ganham nova centralidade nas intervenções urbanas, sobretudo depois da declaração da cidade como patrimônio mundial em 2012. Se, no passado, vencer a história era sinal de modernidade, hoje, as reformas urbanas dialogam com a memória e, em muitos casos, de forma complexa. Em alguns casos, a memória é instrumentalizada e uma espécie de patrimonialização das favelas justifica a reconfiguração 
urbana dessas áreas com um número importante de remoções, reforçando processos de gentrificação. As obras do Porto Maravilha e, em especial as do Morar Carioca no Morro da Providência, paralisadas, aliás, pelo Poder Judiciário a pedido dos próprios moradores, ${ }^{18}$ baseiam-se em parte na discussão do patrimônio arquitetônico local e pretendiam proteger tal patrimônio, removendo o conjunto das casas no cume do morro para garantir a visibilidade da capela do Cruzeiro (Gonçalves, 2013a:20).

Ao tratarmos aqui das duas datas comemorativas da cidade separadas por 50 anos, o que nos moveu não foi buscar coincidências 'cabalísticas' entre as duas datas, mas analisarmos as semelhanças que se dão entre esses processos que se inserem na trajetória da própria cidade, revelando que em ambas o passado representa um obstáculo ao 'progresso' a ser superado. Esse passado representa, na verdade, moradias e moradores que têm sido integrados em larga desvantagem no modelo de cidade que historicamente tem guiado a expansão urbana e o desenvolvimento econômico do Rio.

\section{Referências bibliográficas}

ABREU, Maurício de Almeida. A Evolução Urbana do Rio de Janeiro. 2. ed. Rio de Janeiro: IplanRio, 1997.

BERNADES, Lysia Maria Cavalcanti. Evolução da Paisagem urbana do Rio de Janeiro até o início do século XX. In: ABREU, Maurício (Org.). Natureza e sociedade no Rio de Janeiro. Rio de Janeiro: Prefeitura do Rio de Janeiro, 1992. pp.37-53

BRUM, Mario Sergio. Cidade Alta - Histórias e memórias da remoção e a construção do estigma de favela num conjunto habitacional. Rio de Janeiro: Ponteio, 2012.

. Favelas e remocionismo ontem e hoje: da Ditadura de 1964 aos Grandes Eventos. $O$ Social em Questão. vol. 29, pp. 179-207, PUC-Rio: Rio de Janeiro, 2013.

BURGOS, Marcelo; PEREIRA, Luiz Fernando; CAVALCANTI, Mariana; BRUM, Mario; AMOROSO, Mauro. O Efeito UPP na Percepção dos Moradores das Favelas. Desigualdade \& Diversidade PUC-Rio, vol. 11, pp. 49-97, Rio de Janeiro, 2013.

COMPANHIA ESTADUAL DE ÁGUAS E ESGOTOS - CEDAE. A História do Abastecimento de Água de Cidade do Rio de Janeiro. Rio de Janeiro: CEDAE, 2007.

CEDUG (Comissão Executiva para o Desenvolvimento Urbano) e DOXIADIS ASSOCIATES, Guanabara. Um plano para o desenvolvimento urbano. Rio de Janeiro: CEDUG, 1967.

GONÇALVES, Rafael Soares. Da política de contenção à remoção: aspectos jurídicos das favelas cariocas. In: MELLO, Marco Antonio da Silva; SILVA, Luiz Antonio Machado da; FREIRE, Leticia de Luna; SIMÕES, Soraya Silveira (orgs.), Favelas cariocas. Ontem e hoje. Rio de Janeiro: Garamond, 2012. pp. 253-278.

. Porto Maravilha, Renovação urbana e o uso da noção de risco: uma confluência perversa no Morro da Providência. Libertas, vol. 13, n. 2, p. 1-31, 2013.

18 As obras foram paralisadas diante da falta de informações claras da Prefeitura quanto ao conteúdo das obras e por causa do grande número de remoções sem a respectiva previsão de reassentamento dos moradores. A Prefeitura só teve autorização para continuar as obras do teleférico, que, pronto há um ano, foi inaugurado no segundo semestre de 2014. 
. Favelas do Rio de Janeiro. História e Direito. Rio de Janeiro: Pallas/PUC, 2013.

GUIMARÃES, João. Rio, quatro séculos de mocidade. Rio de Janeiro: Editora Minerva, 1965.

IDEG. A interpenetração das áreas faveladas e áreas industriais no Estado da Guanabara. Rio de Janeiro: IDEG / Centro de Coordenação Industrial para o Plano Habitacional / Centro de Estudos Sócio-Econômicos, 1968.

LACERDA TOMA POSSE dizendo que não vai tolerar comunismo. Jornal do Brasil, p. 4, 06 dez. 1960.

LEEDS, Anthony; LEEDS, Elizabeth. A sociologia do Brasil urbano. Rio de Janeiro: Zahar, 1978.

MARICATO, Ermínia. Cidades no Brasil: neodesenvolvimentismo ou crescimento periférico predatório. Revista Política Social e Desenvolvimento, vol. 1, n. 1, pp 16-57, Campinas: Unicamp, nov. 2013.

MOTTA, Marly Silva da. Cabeça da nação, teatro do poder: a cidade capital como objeto de investigação histórica. Rio de Janeiro: CPDOC, 1993.

. Saudades da Guanabara. O campo político da cidade do Rio de Janeiro (1960-75). Rio de Janeiro: FGV, 2000.

. Entre o castelo e o aterro: a identidade do Rio quatrocentão. In: CARNEIRO, S. de Sá e SANT'ANNA, M. J. G. Cidade: olhares e trajetórias. Rio de Janeiro: Garamond, p.121-135, 2009.

NASSER, David. Rio, perdoa o ingrato. O Cruzeiro, p. 18. 07 maio 1960.

O ESTADO E SEU governador. Editorial, Jornal do Brasil, p. 2, 06 dez. 1960.

OSÓRIO, Mauro. Rio nacional, Rio local: mitos e visões da crise carioca e fluminense. Rio de Janeiro: SENAC, 2005.

PEREZ, Maurício Dominguez. Lacerda na Guanabara. A reconstrução do Rio de Janeiro nos anos 1960. Rio de Janeiro: Odisséia Editorial, 2007.

PLANO ESTRATÉGICO DA PREFEITURA DO RIO DE JANEIRO 2009-2012. Pós 2016: O Rio mais integrado e competitivo. Rio de Janeiro: Prefeitura do Rio de Janeiro, 2009.

PREBISCH, Raul. Problemas teóricos e práticos do crescimento econômico. In: BIELSCHOWSKY, Ricardo (Org). Cinquenta anos de pensamento na Cepal. Rio de Janeiro: Record, 2000.

PREFEITURA DO DISTRITO FEDERAL. Censo das favelas: Aspectos gerais. Rio de Janeiro: Secretaria Geral do Interior e Segurança, Departamento de Geografia e Estatística, 1949.

REZENDE, Vera. Planejamento Urbano e Ideologia. Quatro planos para a cidade do Rio de Janeiro. Rio de Janeiro: Civilização Brasileira, 1982.

SAGMACS (Sociedade de Análises Gráficas e Mecanográficas Aplicadas aos Complexos Sociais). Aspectos Humanos da Favela Carioca [Relatório SAGMACS]. São Paulo: O Estado de São Paulo, 1960.

SANTOS, Vicente Saul Moreira dos. "Minha alma canta, vejo o Rio de Janeiro": a zona sul carioca entre crônicas e canções. Tese de Doutorado em História. PPGHPBC-CPDOC/FGV, Rio de Janeiro, 2013. 
SECRETARIA DE EDUCAÇÃO E CULTURA. O IV Centenário do Rio de Janeiro. V. 2. Rio de Janeiro- GB, 1965.

SILVA, Maria Lais Pereira da. Favelas Cariocas - 1930-1964. Rio de Janeiro: Contraponto, 2005.

A permanência das favelas cariocas e o Plano Doxiadis num contexto de mudanças (1960-1965). In: XII SEMINÁRIO DE HISTÓRIA DA CIDADE E DO URBANISMO, Porto Alegre, 15 a 18 out. 2012.

SOSA, Marisol Rodriguez. A Guanabara de Doxiadis e a Havana de Sert. Ekistics e Urban Design, novas direções na ruptura do CIAM. Tese de doutorado em Arquitetura, PROURB/ UFRJ, 2008.

TAMANINI, Luís Fernando. Brasília, memória da construção. Brasília: Projecto Editorial, 2003.

VALLA, Victor Vincent (Org.). Educação e favela; políticas para as favelas do Rio de Janeiro, 1940-1985. Petrópolis: Vozes, 1986.

VOGEL, Arno; MELLO, Marco Antônio da Silva. Quando a rua vira casa. Rio de Janeiro: IBAM, 1985.

copyright (C) Creative commons Brum, Gonçalves 